Technical note

\title{
Shear strength evaluation of composite pavement with geotextile as reinforcement at the interface
}

\author{
Shyue Leong Lee*, Mohammad Abdul Mannan, Wan Hashim Wan Ibrahim \\ Department of Civil Engineering, Faculty of Engineering, Universiti Malaysia Sarawak, 94300, Kota Samarahan, Sarawak, Malaysia
}

\section{A R T I C L E I N F O}

\section{Keywords:}

Geosynthetics

Polymer concrete

Asphalt concrete

Surface condition

Curing types

Temperature

\begin{abstract}
A B S T R A C T
This research was conducted to investigate the shear strength at the interface between polymer concrete and asphalt concrete with geotextile as reinforcement at the interface of these two types of concrete. The samples were tested for the parameters of different surface conditions [rough and smooth], curing types [room and thermal curing], temperature effect and the impact of geotextile as reinforcement. To investigate the correlation between these parameters, four different testing conditions were implemented. The results showed a significant improvement of shear strength for rough surface sample as compared to smooth surface sample. Moreover, samples cured in oven had lower shear strength as compared to samples cured in room condition. Besides that, high temperature has an adverse impact on the shear strength at the interface between polymer concrete and asphalt concrete due to the weakening of asphalt concrete at high temperature. As for samples reinforced with geotextile, the shear strength resistance was better as compared to unreinforced samples. Through visual observation, the types of failure under all testing conditions were mixed failure mode.
\end{abstract}

\section{Introduction}

Pavement can be divided into flexible pavement, rigid pavement and composite pavement. In general, flexible pavement is a mixture of asphalt and aggregates, rigid pavement is a mixture of cement, water and aggregates, and composite pavement is a combination of flexible pavement laid on top of rigid pavement or vice versa. In this research, a mixture of orthophthalic unsaturated polyester resin [OUPR] and limestone are proposed as polymer concrete [PC] for rigid pavement. This PC is proposed to be placed on top of asphalt concrete [AC] to form composite pavement [CP] with geotextile as reinforcement at the interface between these two types of concrete. Moreover, PC has the potential as rehabilitation material for road maintenance. Hence, investigating the shear strength behavior at the interface of this $\mathrm{CP}$ is important.

Shear strength comes from the interlocking of aggregate, adhesive strength of tack coat and friction at the interface between the two layers of pavement structure (Li et al., 2016) and is measured through shear test which is the most commonly used method (Raposeiras et al., 2013; Zhao et al., 2017). The shear strength at the interface between two layers of pavement structure affects pavement performance such as its mechanical properties, durability and maintenance regime (Rasmussen and Rozycki, 2004; Sprinkel, 2009; Kim et al., 2011; Ge et al., 2015; Li et al., 2016; Hu et al., 2017; Zhao et al., 2017). This is to ensure the pavement layers acts monolithic and functions normally (Raposeiras et al., 2013; Li et al., 2016; Isailović and Wistuba, 2018).

Debonding of interface between two layers of pavement structure led to weak interlaminar strength. It can be caused by one of the three different stress conditions, namely, pure tension, pure shear and mixed condition which is a combination of shear and compressive or tensile stresses (Carreño et al., 2017). Other associated factors are stress caused by shrinkage, traffic load, temperature change, moisture, cycles of freezing and thawing, inappropriate construction techniques or inadequate choice of tack coat and others (Sprinkel, 2009; Ge et al., 2015). Pavement failure due to debonding can be categorised into delamination, slippage, top-down cracking, fatigue cracking, longitudinal cracks, and deformation (Sprinkel, 2009; Li et al., 2013; Ge et al., 2015; Hu et al., 2017; Zhang, 2017; Nithin et al., 2018). All these pavement failures led to adverse impact on traffic safety (Hu et al., 2017) and shorten the service life of pavement (Zhang, 2017). Moreover, these pavement failures are an indicator of shear strength failure (Sprinkel, 2009; Ge et al., 2015).

There are many factors influencing the shear strength between two layers of pavement structure. The factors can be tack coat, geosynthetic [such as woven and non-woven geotextiles, biaxial and multiaxial geogrids], temperature, interface condition, load and other.

\footnotetext{
* Corresponding author.

E-mail addresses: shyueleonglee@hotmail.com (S.L. Lee), mannan@unimas.my (M.A. Mannan), wiwhashim@unimas.my (W.H. Wan Ibrahim).
} 